\title{
ОСОБЕННОСТИ РАЗВИТИЯ МОТИВАЦИИ ДОСТИЖЕНИЯ СТАРШИХ ПОДРОСТКОВ С НАРУШЕНИЕМ ЗРЕНИЯ
}

\section{PECULIARITIES OF DEVELOPMENT OF NEED FOR ACHIEVEMENT AMONG OLDER TEENAGERS WITH VISUAL IMPAIRMENT}

\section{A. Matrokhina \\ S. Khaidov}

Summary: The article presents the urgency of studying the problem of need for achievement among older teenagers with visual impairment, provides and proves a diagnostic programme aimed at examination of this process. The results received through the statistical programme SPSS 21 went through quantitative and qualitative analysis. Following methods were used to analyze the results of the research: correlation analysis of Spearman, Mann-Whitney's U criterion, descriptive statistics.

Keywords: need for achievement, pursuit of success, avoidance of failure, teenagers with visual impairment, diagnostic study.
Матрохина Алина Павловна

Тульский государственный педагогический университет им. Л.Н. Толстого

qwerty8899059@gmail.com

Хачдов Сергей Курбанович

к.nсх.н., доцент, Тульский государственный педагогический университет им. Л.Н. Толстого

haidov@bk.ru

Аннотация: В статье раскрыта актуальность изучения проблемы развития мотивации достижения старших подростков с нарушением зрения, составлена и апробирована диагностическая программа, направленная на изучение данного процесса. Произведен количественный и качественный анализ полученных результатов с помощью статистической программы SPSS 21. Для анализа результатов использовались такие методы, как: корреляционный анализ Спирмена, U-критерий Манна-Уитни, описательная статистика.

Ключевые слова: мотивация достижения, стремление к успеху, избегание неудачи, подростки с нарушением зрения, диагностическое исследование.

\section{Введение}

роблема изучения мотивации достижения старших подростков с нарушением зрения обусловлена тем, что с каждым годом число детей со зрительной патологией неуклонно растет.

Являясь важной ролью в процессе познания окружающего мира, зрение позволяет человеку активно взаимодействовать с социальной действительностью, соотнося с ней свои действия, поступки, поведение. При этом нарушение зрения в основном не влечет за собой серьезных отклонений в психическом развитии, при условии ранней коррекционно-развивающей работы с данной патологией, однако, оно значительно влияет на развитие потребностно-мотивационной сферы личности, приводя в первую очередь к снижению мотивации достижений, что обусловливает отказ от деятельности, снижение активности, неуверенность в себе и своих силах. Кроме этого, ситуацию усложняет то, что зрительная патология не мотивирует подростков к постановке целей, стремлению к достижению успеха, вызывая затруднение в их социальной адаптации, а в дальнейшем и социальной интеграции.

Все это и обусловливает актуальность исследования развития мотивации достижения у старших подростков с нарушением зрения.

\section{^итературный обзор}

Проблемой потребностно-мотивационной сферы, в том числе и мотивации достижения, занимались следующие авторы: М.Ш. Магомед-Эминов [4], Л.И. Солнцева [5,6], А.Г. Литвак [3], Х. Хекхаузен [7], Т.О. Гордеева [1], Е.В. Евтименко [2] и др.

Подростковый возраст выступает важным этапом развития будущей деятельности, где ее успешное, целеустремленное выполнение требует непосредственной активности субъекта. У подростков с нарушением зрения эта активность крайне низка, что непосредственно негативно влияет на формирование мотивации достижения. Нарушение зрения часто вводит человека в состояние стресса, который ведет к развитию возбуждения, дезорганизуя поведение человека, а его дальнейшее усиление - к развитию торможения, обусловливающего пассивность, отказ от деятельности. На этой основе у старших подростков с нарушением зрения наблюдаются страхи и опасения за свое будущее, боязнь того, что они не справятся с порученным делом [3].

При возникновении трудностей выполнения деятельности она часто заменяется подростком на другую, более легкую [5].

Зачастую неадекватная самооценка и уровень притязаний старших подростков с нарушением зрения не по- 
зволяют сформировать адекватное отношение к успеху и неудачам. В связи с этим, у них в большинстве случаев преобладает мотивация к избеганию неудач, являясь ведущей тенденцией.

\section{Методы исследования}

В исследовании использовались следующие методики, позволяющие рассмотреть с разных сторон мотивацию достижения старших подростков с нарушением зрения:

1. «Тест мотивации достижения» А. Мехрабиан (модификация М.Ш. Магомед-Эминов) диагностирует мотивацию достижения со стороны целеполагания и притязаний.

2. «Методика диагностики личности на мотивацию к успеху» (Т. Элерс) рассматривает мотивацию достижения со стороны готовности к риску.

3. «Методика диагностики личности на мотивацию к избеганию неудач» (Т. Элерс) диагностирует мотивацию достижения со стороны оценки собственных возможностей.

4. Методика «Мотивация успеха и боязнь неудачи» (А.А. Реан) позволяет изучить мотивацию достижения с поведенческой стороны, проявляемой в деятельности.

5. «Методика исследования локуса контроля» (Дж. Роттер) выявляет отношение индивида к своим успехам и неудачам.

Количественный и качественный анализ полученных результатов производился с помощью статистической программы SPSS 21. Использовались: корреляционный анализ Спирмена, U-критерий Манна-Уитни, описательная статистика.

Исследование проводилось на базе МБОУ ЦО № 29 г. Тулы. В исследовании приняли участие 15 детей старшего подросткового возраста с нарушением зрения - девочки и мальчики 14-15 лет с такими патологиями, как: слабовидение, частичная атрофия зрительного нерва, высокая степень миопии, астигматизм.

\section{Результаты исследования}

Был проведен анализ эмпирических данных путем описательной статистики, результаты которой представлены в таблице 1.

Как видно из таблицы, по общей выборке мотивация достижений имеет низкий уровень развития, наблюдается тенденция к снижению, что говорит о превалировании мотивации на неудачу. Уровень мотивации к успеху низкий с тенденцией к увеличению. Уровень мотивации к избеганию неудач высокий и имеет тенденцию к возрастанию. Доминирующее стремление имеет средний уровень с тенденцией к снижению, указывающей на стремление избегания неудачи. Экстернальный локус контроля является ведущим.

Результаты исследования по критерию Манна-Уитни не показали статистических различий между мальчиками и девочками, но тем не менее были выделены некоторые количественные различия между ними.

Мотивация достижений имеет низкий уровень, что говорит о направленности на неудачу, как у девочек, так и у мальчиков. Но, стоит отметить, что у девочек тенденция к снижению выражена сильнее, чем у мальчиков.

Мотивация к успеху у мальчиков соответствует среднему уровню, но имеет тенденцию к снижению, в то время как у девочек она находится на низком уровне с тенденцией к увеличению.

Мотивация к избеганию неудач слишком сильно проявляется у девочек, тем самым имеет слишком высокий уровень, в то время как у мальчиков она имеет средний уровень, но с тенденцией к возрастанию.

У девочек показатель ведущего стремления имеет стабильно низкий уровень, что говорит о стремлении к избеганию. Мальчики находятся на границе ведущего стремления, имея средний уровень, но больше склонны к избеганию неудачи, то есть обладают тенденцией к снижению.

Таблица 1

\begin{tabular}{|c|c|c|c|c|c|c|}
\hline & \multicolumn{2}{|c|}{ Средние общая выборка } & \multicolumn{2}{|c|}{ Средние девочки } & \multicolumn{2}{|c|}{ Средние мальчики } \\
\hline & Среднее & Стд. Откл. & Среднее & Стд. Откл. & Среднее & Стд. Откл. \\
\hline Мотивация достижений & 111,2857 & 9,26848 & 101,5000 & 3,53553 & 115,2000 & 7,66159 \\
\hline Мотивация к успеху & 10,8571 & 2,73426 & 9,0000 & 1,41421 & 11,6000 & 2,88097 \\
\hline Мотивация к избеганию неудачи & 18,4286 & 3,55233 & 22,5000 & 2,12132 & 16,8000 & 2,48998 \\
\hline Стремление к достижению/избеганию & 8,7143 & 1,70434 & 7,0000 &, 00000 & 9,4000 & 1,51658 \\
\hline Экстернальный локус контроль & 12,5714 & ,97590 & 12,5000 & ,70711 & 12,6000 & 1,14018 \\
\hline Интернальный локус контроль & 10,4286 & ,97590 & 10,5000 & 70711 & 10,4000 & 1,14018 \\
\hline
\end{tabular}


Как у мальчиков, так и у девочек показатель экстернальности является превалирующим.

Корреляционный анализ по Спирмену выявил прямые (положительные) и обратные (отрицательные) связи значений двух переменных в группе исследуемых. Было выявлено, что, чем выше мотивация к избеганию неудачи, тем ниже мотивация достижений $(\mathrm{Cr}=-0,767$; $p=0,044)$. Это говорит о том, что, чем выше негативная оценка собственных возможностей, тем ниже целеустремленность по отношению к достижениям.

Удалось выявить прямую связь между мотивацией к успеху и доминирующим стремлением $\left(C_{r}=0,854 ; \mathrm{p}=\right.$ 0,014): чем выше мотивация к успеху, тем выше будет и само стремление к нему. Высокая мотивация к успеху в данном случае определяет адекватный уровень риска, что непосредственно влияет на повышение стремления к достижению успеха в деятельности.

Наблюдается прямая связь между полом и мотивацией избегания неудачи $\left(C_{r}=0,820 ; p=0,024\right)$, что на основе средних показателей говорит о том, что, чем выше мотивация к избеганию неудачи, тем больше она проявляется у лиц женского пола.

Можно сказать об отрицательной связи между экстернальным и интернальным локусом контроля $\left(C_{r}=-1,000\right)$. В данном случае, у подростков сильнее проявление экстернального локуса.

\section{Выводы}

Таким образом, мы видим, что в целом результаты по каждому из показателей, касаемых достижений, представлены низкими и приближенными к низким значениями с тенденцией к снижению. Показатель же к избеганию имеет высокий уровень и тенденцию к увеличению. Но, стоит отметить, что потенциал к улучшению результатов выше у мальчиков, чем у девочек. Это связано с тем, что у девочек в большинстве случаев наблюдаются низкие значения показателей с тенденцией к снижению, а тенденция к избеганию неудачи представлена слишком высоким уровнем проявления. У мальчиков также в большинстве случаев наблюдаются тенденции к снижению, но результаты показателей в основном представлены в среднем значении. Учитывая значения показателей и превалирующие тенденции, можно сказать о том, что зрительная патология более негативно влияет на развитие потребностно-мотивационной сферы лиц женского пола, чем мужского. Результаты исследования также позволяют определить направления реабилитационных и коррекционных воздействий для старших подростков с нарушением зрения.

\section{ЛИТЕРАТУРА}

1. Гордеева Т.0. Психология мотивации достижения. - М .: Смысл; Издательский центр «Академия», 2006. 336 с.

2. Евмененко Е.В. Психология лиц с нарушениями зрения /Е. В. Евмененко, А. В. Трущелева — Ставрополь: Изд-во СГПИ, 2008. 220 с.

3. Литвак А.Г. Психология слепых и слабовидящих: учеб.пособие / Рос. гос. пед. ун-т им. А.И. Герцена. СПб.: Изд-во РГПУ, 1998. 271с.

4. Магомед-Эминов М.Ш. Мотивация достижения :структура и механизмы: автореф. дис. канд. психол. наук / Мадруддин Шамсуддинович Магомед-Эминов. Москва, 1987.

5. Солнцева Л.И., Денискина В.З. Психология воспитания ребенка с нарушением зрения - М.: Налоговый вестник, 2004. 320 с.

6. Солнцева Л.И. Тифлопсихология детства. М.: «Полиграф сервис», 2000. 127 с.

7. Хекхаузен Х. Психология мотивации достижения / Хекхаузен Х. Санкт-Петербург: Речь,2001. 